\title{
Rainfall seasonality on landslide probability: a modelling approach
}

\author{
Estefanía Muñoz ${ }^{1, a}$ and Andrés Ochoa ${ }^{1}$ \\ ${ }^{1}$ Departament of Geosciences and Environment, National University of Colombia, Colombia
}

\begin{abstract}
Precipitation is one of the main landslides triggering factors because the amount of infiltrated water into the ground causes changes in pore pressure due to the decrease in suction or the rising water table level. In this paper we estimated the return period of landslides from a rainfall stochastic behavior. Using rainfall intensity and duration probability density functions (pdf) and Philip's infiltration model, the pdf of water infiltrated volume into the soil was obtained. Then, assuming the soil reaches saturation, the pdf of depth wetting front $\left(\mathrm{z}_{\mathrm{w}}\right)$ was obtained. Finally, with $\mathrm{z}_{\mathrm{w}}$ and the Mohr-Coulomb rupture criteria, the pdf of the Factor of Safety (FS) was determined. Subsequently, landslide occurrence was analyzed under different hydroclimatic scenarios, such as dry and wet seasons and El Niño Southern Oscillation (ENSO) phases. The occurrence of shallow landslides depends more on intensity storm than duration storm, and they are more likely to happen during La Niña phase than during El Niño phase because both storm duration and storm intensity tend to increase.
\end{abstract}

\section{Introduction}

Most landslides occur on rainiest months [1], showing the close relation between the hydroclimatic conditions as a triggering factor and the occurrence of landslides.

Landslides triggered by rainfall, known as "soil slip", are characterized for having superficial failure surfaces (between 1 and 3 meters) and parallels to the slope face. This type of movements are due to changes on soil pore pressure when a wetting front product of infiltration advances [2].

The problem with rainfall as a triggering factor has been approached using physical and statistical models. Physical models are generally based on the combination of classical hydrological mechanisms (e.g. [3-7]). Statistical models have been used from different approaches, among which are the definition of critical thresholds that relate rainfall events intensity and duration with landslides occurrence (e.g. [8-12]), and the search for relations between landslide geometrical characteristics (perimeter, area and volume) and their frequency of occurrence for different climatological scenarios (e.g. [13-16]).

In this paper was analyzed the effect of annual and interannual seasonality (ENSO phenomenon) of precipitation on the stability of a hypothetical slope. From rainfall statistical behavior, the landslide occurrence probability on a slope was obtained, assuming that it fails when de factor of safety (FS) is less than 1. Through deterministic models of infiltration, wetting front depth and factor of safety, the rainfall probability density functions (pdf) was transformed into pdf of FS.

\footnotetext{
a Corresponding author: emunozh@unal.edu.co
}

\section{Landslide probability}

Starting from the historical behavior of the precipitation series and through infiltration models, it is possible to estimate infiltrated volume per unit area (e.g. $[17,18])$. There were used very simple models for rainfall, infiltration, wetting front depth and FS due to the mathematical difficulty to relate them analytically.

\subsection{Rainfall model}

Rainfall was modeled using a rectangular pulse Poisson model with exponential density distributions for average intensity $i_{r}$ and total duration of the storms $t_{r}$, assumed as independent variables, as proposed by Eagleson [19].

To each point of the process are associated rectangular pulses with random durations and intensities. As shown in Figure 1, the intensity at each instant corresponds to the active rectangles overlapping at that time.

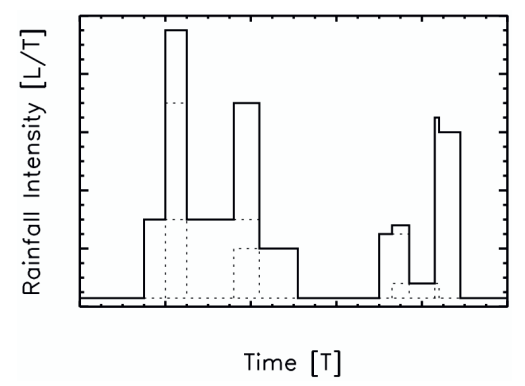

Figure 1. Rectangular pulse Poisson model. 
Probability density functions of mean intensity and mean total duration of the storms are given by

$$
\begin{aligned}
& f_{I_{r}}\left(i_{r}\right)=\beta e^{-\beta i_{r}}, i_{r} \geq 0 \\
& f_{T_{r}}\left(t_{r}\right)=\delta e^{-\delta t_{r}}, t_{r} \geq 0
\end{aligned}
$$

where, $\beta$ y $\delta$ are the inverse of the mean intensity and the total duration respectively.

\subsection{Infiltration model}

The model proposed by Philip [20] was used as an infiltration model, in which the infiltration capacity $f(t)$ is defined according to saturated hydraulic conductivity $k_{s}$ and soil sorptivity $S$. The potential infiltration capacity $f^{*}(t)$ and infiltrated volume $F^{*}(t)$ per unit area are

$$
\begin{gathered}
f^{*}(t)=k_{s}+\frac{1}{2} S t^{-\frac{1}{2}} \\
F^{*}(t)=k_{s} t+S t^{\frac{1}{2}}-k_{s} t_{0}-S t_{0}^{\frac{1}{2}}+i t_{0}
\end{gathered}
$$

where, $t_{0}$ is time of ponding, that occurs when infiltration rate matches rainfall intensity, defined by

$$
t_{0}=\frac{S^{2}}{4\left(i-k_{s}\right)^{2}}
$$

In order to calculate $f^{*}(t)$ and $F^{*}(t)$ it was stablished the relation between the storm mean intensity and soil saturated hydraulic conductivity. When the intensity is higher than the hydraulic conductivity it comes a time where the soil does not have enough capacity to infiltrate the water from the atmosphere $\left(t_{0}\right)$, turning part of it on runoff water (Figure 2). When $i_{r}<k_{s}$ all the storm water infiltrates because the capacity of the soil to intake water is never exceeded (Figure 3).

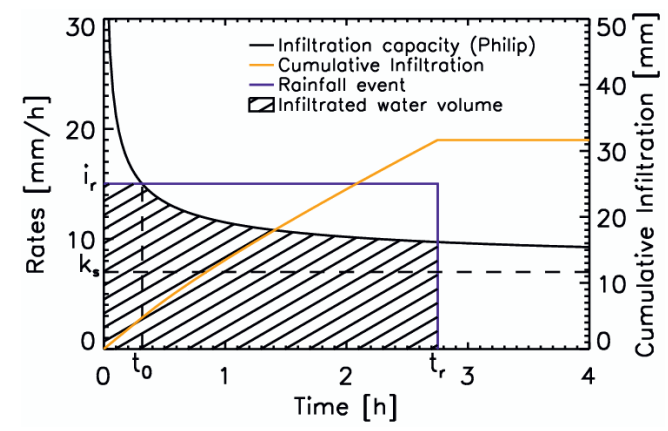

Figure 2. Infiltration when storm intensity is greater than or equal to saturated hydraulic conductivity.

In Figure 2 and Figure 3, blue rectangle represents the storm, the solid black line is the infiltration capacity given by Philip's model and the yellow line is the cumulative infiltration. The hatched area within the blue rectangle and below the infiltration capacity is the infiltrated water volume, and the unshaded area of the rectangle is the runoff volume $R(t)$, given by

$$
R(t)=\left\{\begin{array}{cc}
0, & i_{r}>k_{s} \wedge 0<t<t_{0} \\
{\left[\frac{S}{2 \sqrt{i_{r}-k_{s}}-\sqrt{i_{r}-k_{s}} t^{2}}\right]^{2},} & i_{r}>k_{s} \wedge t_{0}<t<t_{r} \\
0, & i_{r}<k_{s} \wedge \forall t
\end{array}\right.
$$

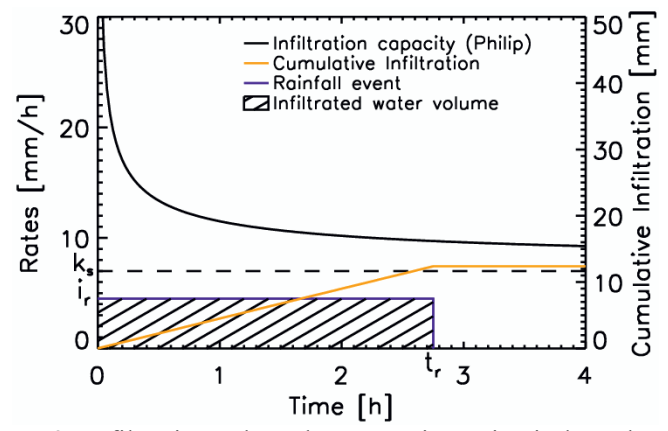

Figure 3. Infiltration when the storm intensity is less than the saturated hydraulic conductivity.

And the infiltrated volume per unit area $F(t)$ by

$$
F(t)=i_{r} t_{r}-R
$$

\subsection{Wetting front model}

The depth of wetting front $z_{w}(t)$, that is to say, the maximum depth in which soil moisture varies with infiltrated volume per unit area, was calculated with modification of the equation proposed by Lumb [21]

$$
z_{w}(t)=\frac{F(t)}{n\left(S_{\mathrm{wf}}-\mathrm{S}_{\mathrm{wi}}\right)}
$$

where, $F(t)$ is infiltrated water volume at time $t$ of storm, $n$ is soil porosity and $S_{w f}$ and $S_{w i}$ are final and initial degree of saturation respectively.

\subsection{Slope stability model}

With the Mohr-Coulomb rupture criteria and assuming an infinite slope, the relation to find the factor of safety FS was

$$
F S(t)=\frac{c^{\prime}+\left(\gamma_{\mathrm{T}}-\gamma_{w}\right) z_{w}(t) \cos ^{2} \alpha \tan \phi^{\prime}}{\gamma_{\mathrm{T}} z_{w}(t) \sin \alpha \cos \alpha}
$$

where, $c^{\prime}$ and $\phi^{\prime}$ are soil cohesion and friction angle of soil respectively, $\gamma_{\mathrm{T}}$ is the soil unit weight, $\gamma_{\mathrm{w}}$ is the unit weight of water and $\alpha$ is the slope angle. 


\section{Rainfall seasonality effect on landslides}

Mechanical and hydraulic parameters of hypothetical slope considered are presented on Table 1. The soil parameters correspond to a silt loam soil.

Table 1. Parameters of the slope and the soil that forms it.

\begin{tabular}{|c|c|}
\hline Parameter & Value \\
\hline$S\left[\mathrm{~mm} \mathrm{~h}^{1 / 2}\right]$ & 10 \\
\hline$k_{s}[\mathrm{~mm} / \mathrm{h}]$ & 35 \\
\hline$\theta_{w i}$ & 0.28 \\
\hline$\theta_{w f}$ & 0.40 \\
\hline$n$ & 0.45 \\
\hline$c[\mathrm{kPa}]$ & 10 \\
\hline$\phi\left[^{\circ}\right]$ & 25 \\
\hline$\alpha\left[^{\circ}\right]$ & 45 \\
\hline$\gamma_{T}\left[\mathrm{kN} / \mathrm{m}^{3}\right]$ & 17.5 \\
\hline
\end{tabular}

The influence of the annual cycle on precipitation and the presence of macro climatic phenomenon like ENSO generate a great variability on rainfall, which implicates variability on soil infiltrated water content and consequently, on slope stability. The annual cycle indicates seasons with higher or lower precipitations along the year, while the presence of warm phase of ENSO (El Niño) leads to decreasing the average precipitation on different timescales and cold phase (La Niña) leads to increasing in most parts of Colombia [22].

For this paper the data analyzed correspond to Miguel de Aguinaga station, located in the city of Medellín, Colombia. This information has a temporary resolution of 15 minutes for an 11 year period (16/03/2001 to 24/05/2012).

The wet and dry seasons were defined from the annual cycle of the precipitation series, which presents rainy and dry periods, with a bimodal distribution. Periods between the months of April-May-June and September-OctoberNovember were defined as the wet season and DecemberJanuary-February-March and July-August as the dry season, due to the fact that they have highest and lowest precipitations respectively.

Interannual variability due to ENSO phenomenon was estimated by dividing the historical precipitation series in three sets correspondent to the three ENSO phases: El Niño, Normal, and La Niña. The periods on which the phases occur are reported by the NOAA (National Oceanic and Atmospheric Administration) using the Oceanic Niño Index (ONI).

Table 2 and Table 3 show the inverse of the intensity and duration respectively for ENSO phases, climate seasons and combinations between them.

Table 4 shows the precipitation of the mean storm, calculated as the multiplication of the inverse of $\beta$ and $\delta$.

The wet season storms have longer durations but less intensities, while dry season storms are more intense but much shorter.
Table 2. Inverse of the mean intensity $\beta[\mathrm{h} / \mathrm{mm}]$.

\begin{tabular}{|c|c|c|c|c|}
\hline & El Niño & Normal & La Niña & General \\
\hline Dry & 0.44 & 0.41 & 0.36 & 0.40 \\
\hline Wet & 0.41 & 0.43 & 0.36 & 0.41 \\
\hline General & 0.42 & 0.43 & 0.36 & $\mathbf{0 . 4 0}$ \\
\hline
\end{tabular}

Table 3. Inverse of the mean duration $\delta\left[\mathrm{h}^{-1}\right]$.

\begin{tabular}{|c|c|c|c|c|}
\hline & El Niño & Normal & La Niña & General \\
\hline Dry & 1.44 & 1.51 & 1.47 & 1.48 \\
\hline Wet & 1.42 & 1.39 & 1.29 & 1.37 \\
\hline General & 1.43 & 1.43 & 1.36 & $\mathbf{1 . 4 1}$ \\
\hline
\end{tabular}

Table 4. Mean precipitation $\mathrm{P}[\mathrm{mm}]$.

\begin{tabular}{|c|c|c|c|c|}
\hline & El Niño & Normal & La Niña & General \\
\hline Dry & 1.60 & 1.62 & 1.89 & 1.70 \\
\hline Wet & 1.72 & 1.66 & 2.14 & 1.79 \\
\hline General & 1.68 & 1.65 & 2.03 & $\mathbf{1 . 7 6}$ \\
\hline
\end{tabular}

Storms during La Niña phase are significantly more intense and lasting, and storms during El Niño phase, even though mean duration is the same as Normal phase, the mean intensity increases a little.

Storms in periods where dry season and La Niña phase concur are more intense, and the storms when dry season and El Niño phase concur are less intense, but rainfalls last more than those on the same season during La Niña and Normal phases.

During wet season, there are only high intensities when it concurs with La Niña phase, which also has the longest durations. When it concurs with El Niño and Normal phases, there is only an increase of duration.

During wet season, the average precipitation $(\mathrm{P})$ is higher than during dry season. During cold phase of ENSO, $\mathrm{P}$ increases on both weather seasons, while on warm phase only increases when it concurs with wet season, because the storms tend to intensify.

The frequency curves of infiltrated water volume $(\mathrm{F})$, wetting front depth $\left(\mathrm{Z}_{\mathrm{w}}\right)$ and factor of safety (FS) for different seasonal scenarios were calculated. Figure 4 shows the curves for dry, wet, and multi-annual seasons. The return period ( $\mathrm{Tr}$ ) for the three variables during wet and dry season is less than the average regime, as they are related to the probability that certain value of FS occurs and at the same time a dry or wet season occur.

The return period for FS equal to 1 is higher for wet season than for dry season, indicating that according to the models, the more intense rainfall events, although shorter, have the tendency to trigger more superficial landslides than those with longer duration and less intensity. This result was obtained under the assumption that the initial soil moisture is the same before each storm. 


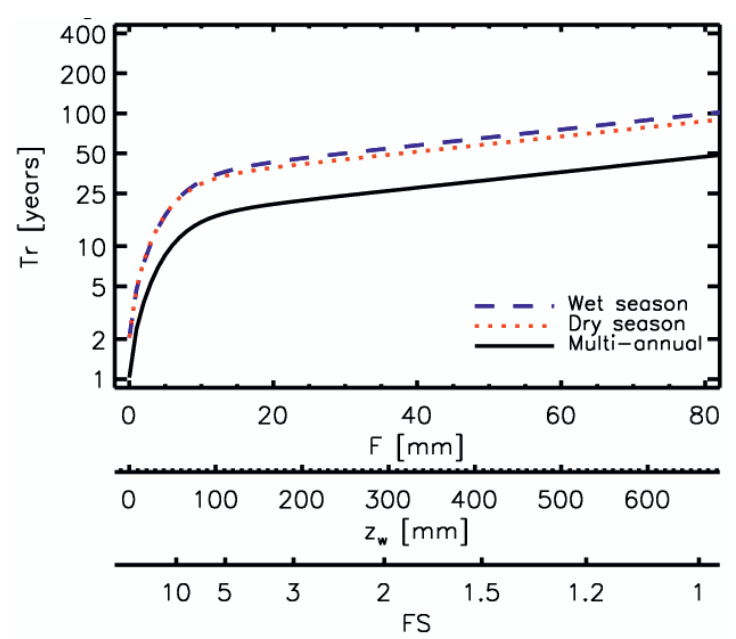

Figure 4. Return period of F, $\mathrm{Z}_{\mathrm{w}}$ and FS multi-annual, dry and wet seasons.

Figure 5 shows the return period of $F, z_{w}$ and $F S$ for the three phases of ENSO. Tr values on Normal phase are less than those of El Niño and La Niña, since most of the time it is on Normal phase. FS equal to 1 , on average, occurs more frequently during La Niña than during El Niño, because during La Niña more rainfall events with longer durations and higher intensity occur.

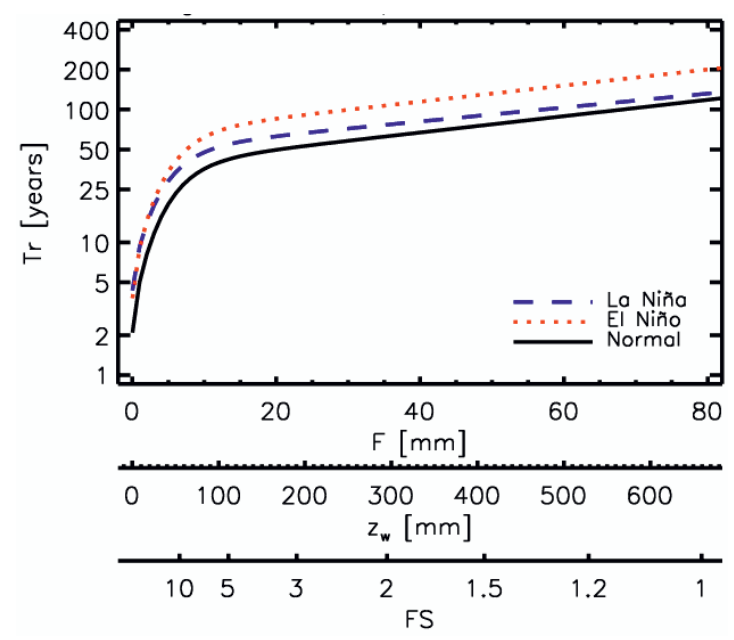

Figure 5. Return period of $F, Z_{w}$ and $F S$ for the ENSO phases.

Figure 6 shows the return period for the seasons in which ENSO phases concur with the different rainfall seasons. During La Niña on wet and dry season, the return periods are very similar because the mean intensities of the rainfall events are very alike. The return period for El Niño during wet season is less than during wet season, since the intensities are higher. The same happens on the Normal periods.

The higher return period occur during El Niño for both rainfall seasons, and the lower for the Normal phase as they are the most probable situation.

\section{Conclusions}

The stability of a hypothetical slope has been analyzed under different climate scenarios, considering that probabilistic behavior of factor of safety is given by rainfall, while the other parameters involved are deterministic.

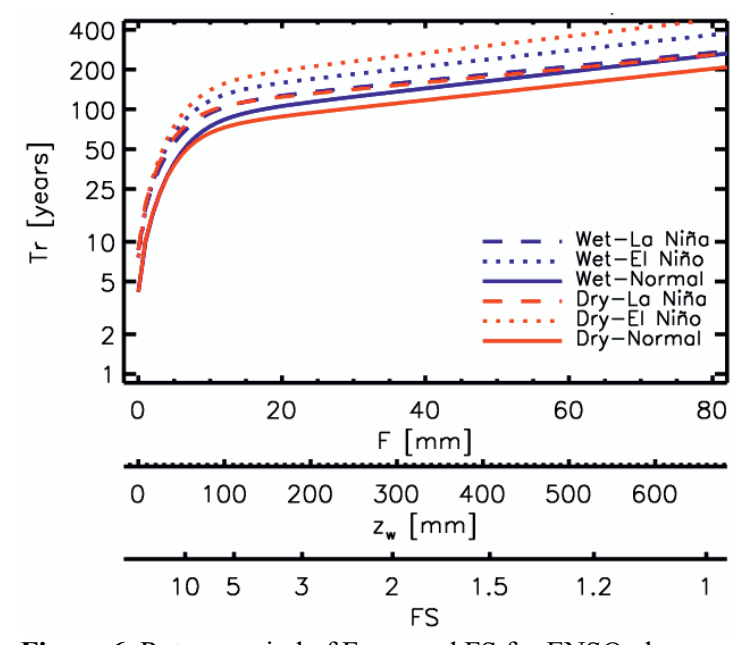

Figure 6. Return period of F, zw and FS for ENSO phases during wet and dry seasons.

The superficial landslides occurrence depends strongly on storm intensity more than on storm duration; therefore, it is more probable landslides occur during dry seasons, where storms tend to intensify.

During La Niña phase it is always more likely that landslides occur than during El Niño because storm durations and intensities tend to increase.

In the long term more landslides occur during Normal phase of ENSO than during El Niño and La Niña. This effect occurs because Normal phase is the most frequent.

These conclusions are valid only for slopes similar to the slope analyzed, and under climatic conditions such as the pluviometric station considered. Furthermore, the different models considered assume important simplifications. The Philip's infiltration model is a simplified solution to the Richard's equation in one dimension, so it does not consider lateral flows. Also, it assumes hydraulic conductivity and sorptivity coefficients constant in time and space. The wetting front model assumes a homogeneous and isotropic soil, and it reaches saturation to the depth $\mathrm{z}_{\mathrm{w}}$. In reality, moisture decreases progressively with depth. Additionally, the initial and final moisture must be known. The slope stability model assumes an infinite slope and a failure surface parallel to the ground surface, located at the same depth as $Z_{\mathrm{w}}$.

On the other hand, the simulation does not consider the effect of vegetation, heat water losses and the water table influence.

\section{Acknowledgements}

The authors thank COLCIENCIAS (Colombia) for their financial support.

\section{References}

1. É. Aristizábal, J. Gómez, E. Aristizábal, and J. 
Gómez, Gestión Y Ambient. 10, 17 (2007).

2. T. W. J. Van Asch, L. P. H. Van Beek, and T. A. Bogaard, in 1st Ital. Work. Landslides. RainfallInduced Landslides Mech. Monit. Tech. Nowcasting Model. Early-Warning Syst., edited by L. Picarelli, P. Tommasi, G. Urciuoli, and P. Versace (Naples, 2009).

3. L. Chen and M. H. Young, Water Resour. Res. 42, 1 (2006).

4. S. E. Cho and S. R. Lee, Comput. Geotech. 28, 185 (2001).

5. S. E. Cho, Eng. Geol. 105, 32 (2009).

6. I. Egeli and H. F. Pulat, Sci. Iran. 18, 1179 (2011).

7. S. Oh and N. Lu, Eng. Geol. 184, 96 (2015).

8. P. Frattini, G. Crosta, and R. Sosio, Hydrol. Process. 23, 1444 (2009).

9. T. V. Hromadka II, T. V. Hromadka III, and M. Phillips, Environ. Eng. Geosci. XVI, 343 (2010).

10. P. Tarolli, M. Borga, K.-T. Chang, and S.-H. Chiang, Geomorphology 133, 199 (2011).

11. M. T. J. Terlien, Environ. Geol. 35, 124 (1998).

12. M. N. Papa, V. Medina, F. Ciervo, and a. Bateman,
Hydrol. Earth Syst. Sci. 17, 4095 (2013).

13. B. D. Malamud, D. L. Turcotte, F. Guzzetti, and P. Reichenbach, Earth Surf. Process. Landforms 29, 687 (2004).

14. J. F. Tiga, Análise Espacial E Estatística Dos Movimentos de Massa Deflagrados Pelas Chuvas Dos Dias 11 E 12 de Janeiro de 2011 Na Região Serrana Do Estado Do Rio de Janeiro, Brasil, Master, 2013.

15. M. Alvioli, F. Guzzetti, and M. Rossi, Geomorphology (2014).

16. F. C. Dai and C. F. Lee, Eng. Geol. 59, 253 (2001).

17. P. S. Eagleson, Water Resour. Res. 14, 741 (1978).

18. N. K. Goel, R. S. Kurothe, B. S. Mathur, and R. M. Vogel, J. Hydrol. 228, 56 (2000).

19. P. S. Eagleson, Water Resour. Manag. 8, 878 (1972).

20. J. R. Philip, Soil Sci. 83, 345 (1957).

21. P. Lumb, Q. J. Eng. Geol. Hydrogeol. 8, 31 (1975).

22. G. Poveda and O. Mesa, Meteorol. Colomb. 5, 3 (2002). 